\title{
Self-Efficacy and Nomophobia in Nurses in Indonesia
}

\section{Wahyu Anggoro,"* and Hanny Handiyani²}

${ }^{1}$ Bachelor of Nursing Program, Faculty of Nursing, Universitas Indonesia, Depok, Indonesia ${ }^{2}$ Department of Basic Nursing and Nursing Science, Faculty of Nursing, Universitas Indonesia, Depok, Indonesia

\section{ORCID}

Wahyu Anggoro: https://orcid.org/0000-0001-6752-451X

Corresponding Author: Wahyu Anggoro; email:

wahyu.anggoro618@gmail.com

Published: 7 February 2022

Publishing services provided by Knowledge E

(c) Wahyu Anggoro and Hanny Handiyani. This article is

distributed under the terms of the Creative Commons

Attribution License, which

permits unrestricted use and redistribution provided that the original author and source are credited.

Selection and Peer-review under the responsibility of the IVCN Conference Committee.

\section{G OPEN ACCESS}

Abstract. This study aimed to determine the relationship between self-efficacy and the level of nomophobia (the fear of being detached from a smartphone) in nurses. This was a descriptive correlative study with a cross-sectional design, where 113 respondents were selected using quota sampling techniques. Data collection was through the Nomophobia Questionnaire and General Self-Efficacy Scale. The study was conducted from June 6 until July 10, 2020, at Hospital X in Bandung, Indonesia. Analysis of the data was through univariate analysis (frequency distribution) and bivariate analysis (Chi-square and Spearman's correlation test). The results showed that most of the respondents were female (66.4\%), and ages ranged between 26 - 56 years old with a mean of 37 years old. The minimum and maximum length of work were 1 and 34 years, respectively. The study showed a significant relationship between the cost of using a smartphone and the level of nomophobia. It also showed a relationship between self-efficacy and the level of nomophobia among nurses from $X$ hospital in Bandung ( $p<0.05$ ). Generally, nurses with lower self-efficacy showed a higher degree of nomophobia. These results may be used in developing clear regulations regarding restricting smartphone usage in hospitals and formulating work strategies. This would improve and maintain the nurses' self-efficacy as an effort to increase the quality of nursing care services as well as patient satisfaction and safety in the hospital.

Keywords: self-efficacy, nomophobia, nurse, smartphone

\section{Introduction}

Increase of smartphone usage will lead to an anxious situation known as nomophobia. Nomophobia symptom is the usage of smartphone in a danger category, not appropriate, and excessive $[1,2,3]$. Study said that $67 \%$ of nurses use their personal phone while working [4]. The main reason uttered is to maintain professional work communication. Survey on 1921 respondents, found out that $83 \%$ of the respondents said they have used smartphone, 58-78\% said they used smartphone while working for professional aims, and $43 \%$ used their phones to access social media and look for work related information [5]. 
Usage of smartphone during workhours will give consequences. Several studies claimed serious impacts of nomophobia which are decrease of attention, decrease of memorizing important things, procrastinating tasks, creating big source of disturbance, and causing disconnection of one and their surroundings are several consequences that can happen $[6,7]$.

Self-efficacy is believed as a psychosocial protection from nomophobia $[8,9]$. Research on nomophobia topic exist, but the research on self-efficacy and nomophobia is still limited so it is still unsurely known. Factors affecting nomophobia level on nurses should be able to be identified to define prevention measures and appropriate controlling This research aimed to identify the relationship between self-efficacy and nomophobia level on nurses from $X$ hospital in Bandung.

\section{Method}

This research is a descriptive correlation with cross-sectional design approach. Respondents were chosen using quota sampling technique with 113 respondents acquired. Data collection used Google form consisted of General Self-Efficacy Scale (GSES) instrument to measure self-efficacy. GSES instrument Indonesian version consisted of 10 items. Minimum score is 10 and maximum score is 40 , median value was used to determine between low and high self-efficacy. Nomophobia Questionnaire (NMP-Q) were used to measure level of nomophobia. NMP-Q Indonesian version consisted of 20 items, each item had minimum 1 score and maximum 7 score. Total score was categorized based on the instrument recommendation. Validity and Reliability test of both instruments used the Cronbach's Alfa value and was done to 30 respondents apart from the research samples.

Data collection was carried out after passing ethical consideration by Komite Etik Penelitian FIKUI with letter number SK-33/UN2.F12.D1.2.1/ETIK 2020. Data was collected with Google form. Respondents were given description about the research and informed consent on the form's front page. Should the respondents agree, respondents can continue to the next page. The confidentiality of all information will always be kept and there is no element of coercion in this research.

Univariate analysis shows the distribution of frequency from all studied variables which are demographic (age, sex, marital status, educational level, employment period, frequency, cost and duration of smartphone usage), self-efficacy, and level of nomophobia. Bivariate analysis was used to know the relationship between independent variables (self-efficacy) and confounding variable (demography) with the dependent 
TABLE 1: Distribution of Frequency of Respondents based on Demographic Data, Usage Duration, Usage Frequency, Monthly Incurred Cost, and Number of Smartphone Owned on X Hospital Bandung ( $n=113$ ).

\begin{tabular}{|c|c|}
\hline Variable & n (\%) \\
\hline $\begin{array}{l}\text { Age (Mean } \pm \text { SD) Min }=26 \text { Years old Max }= \\
56 \text { Years old Sex Male Female Marital Status } \\
\text { Single/Not Married Married Educational Level } \\
\text { D3 (Vocational) D4/ S1 (Bachelor) S1 + Profesi } \\
\text { (Professional) Magister (Master) Magister }+ \\
\text { Spesialis (Master and Specialist) Employment } \\
\text { period (Mean } \pm \text { SD) Min }=1 \text { Years Max }=34 \\
\text { Years Usage Duration (Mean } \pm \text { SD) Min }=1 \\
\text { Hour Max }=16 \text { Hours Usage Frequency (Mean } \\
\pm \text { SD) Min }=3 \text { times Max }=30 \text { times Number } \\
\text { of Smartphone One (1) Two (2) Monthly } \\
\text { Smartphone Cost (Mean } \pm \text { SD) Min }=20.000 \\
\text { Max }=550.000\end{array}$ & $\begin{array}{l}37.19 \pm 6.38738(33.6) 75(66.4) \\
12(10.6) 101(89.4) 59(52.2) 4 \\
(3.5) 46(40.7) 3(2.7) 1(0.9) \\
13.72 \pm 6.6795 .73 \pm 3.293 \\
12.08 \pm 5.931109(96.5) 4(3.5) \\
130725.66 \pm 71384.303\end{array}$ \\
\hline
\end{tabular}

variable (level of nomophobia). Statistical test used are the Chi-Square hypothesis test, Gamma, and Spearman Correlation.

\section{Result}

\subsection{Characteristics Figures of Nurses}

Table 1 showed the youngest age of the respondent was 26 years old and the eldest was 56 years old with mean of age at 37 years old $(S D=6.387)$. More than half of the respondents were female (66.4\%). Most of the respondents were married (89.4\%). The educational levels of the respondents were $52.2 \%$ have Diploma III qualification (Vocational) and $40.7 \%$ have Sarjana + Profesi qualification (Professional). Employment period of the respondents varied from 1 to 34 years with mean score at 13.72 (SD = 6.679).

Duration of respondents' smartphone usage in a day varied from 1 to 16 hours with mean score $5.73(S D=3.293)$. Most of the respondent have 1 smartphone $(96.5 \%)$, with the frequency of usage a day was 3 to 30 times with mean score 12.08 (SD = 5.931). The lowest cost expensed by the respondent in a month was Rp. 20.000 and the highest cost was Rp.550.000 with mean score 130.725,03 (SD = 71.384, 886).

\subsection{Self-Efficacy Description Based on Nurse Characteristics}

Table 2 showed that respondent who had a high self-efficacy were from male respondents $(22.1 \%)$ and female (40.7\%). More than half of the total respondent who already married had a high self-efficacy (53.9\%). Respondents with DIII (Vocational) and 
TABLE 2: Distribution of Frequency of Nurses' Self-efficacy in X Hospital in Bandung ( $n=113)$

\begin{tabular}{|c|c|c|c|c|}
\hline \multirow[t]{3}{*}{ Variable } & \multicolumn{4}{|c|}{ Self-efficacy } \\
\hline & \multicolumn{2}{|c|}{ Low } & \multicolumn{2}{|c|}{ High } \\
\hline & $\mathbf{n}$ & $\%$ & n & $\%$ \\
\hline Sex Male Female & 1329 & 11.525 .7 & 2546 & 22.140 .7 \\
\hline $\begin{array}{l}\text { Marital Status Single/Not Mar- } \\
\text { ried Marrieds }\end{array}$ & 240 & 1.835 .4 & 1061 & 8.953 .9 \\
\hline $\begin{array}{l}\text { Educational Level D III (Voca- } \\
\text { tional) D IV/ S1 (Bachelor) S1 + Pro- } \\
\text { fesi (Professional) S2 (Master) S2 } \\
+ \text { Spesialis (Master + Specialist) }\end{array}$ & $\begin{array}{l}254121 \\
0\end{array}$ & $\begin{array}{ll}22.1 & 3.5 \\
10.6 & 0.9 \\
0 & \end{array}$ & $\begin{array}{l}340342 \\
1\end{array}$ & $\begin{array}{lr}30.1 & 0 \\
30.1 & 1.8 \\
0.9 & \end{array}$ \\
\hline Self-efficacy & 42 & 37.2 & 71 & 62.8 \\
\hline
\end{tabular}

TABLE 3: Distribution of Frequency of Nurses' Level of Nomophobia in X Hospital in Bandung ( $n=113$ )

\begin{tabular}{|c|c|c|c|}
\hline \multirow[t]{2}{*}{ Variable } & \multicolumn{3}{|c|}{ Level of Nomophobia } \\
\hline & Mild & Moderate & Severe \\
\hline & n (\%) & n (\%) & n (\%) \\
\hline Sex Male Female & 9 (7.9) 12 (10.6) & $\begin{array}{ll}24 & (21.2) \quad 47 \\
(41.6) & \end{array}$ & $5(4.4) 16(14.3)$ \\
\hline $\begin{array}{l}\text { Marital Status Single/Not Married } \\
\text { Married }\end{array}$ & 3 (2.6) 18 (15.9) & 8 (7.1) 63 (55.8) & 1 (0.9) 20 (17.7) \\
\hline $\begin{array}{l}\text { Educational Level D III (Vocational) } \\
\text { D IVI S1 (Bachelor) S1 + Profesi } \\
\text { (Professional) S2 (Master) S2 + } \\
\text { Spesialis (Master+Specialist) }\end{array}$ & $\begin{array}{l}12(10.6) 1(0.9) \\
8(7.1) 0(0) 0(0)\end{array}$ & $\begin{array}{l}35(30.9) 2(1.8) \\
31(27.4) 2(1.8) \\
1(0.9)\end{array}$ & $\begin{array}{l}12(10.6) 1(0.9) \\
7(6.2) 1(0.9) 0 \\
(0)\end{array}$ \\
\hline Nomophobia & $21(18.6)$ & $72(63.7)$ & 20 (17.7) \\
\hline
\end{tabular}

S1+Profesi (Professional) degree who had a high self-efficacy were 34 respondents (30.1\%).

\subsection{Figure of Level of Nomophobia based on Nurse's Characteris- tics}

Table 3 explains that level of nomophobia based on sex, female had level of nomophobia in moderate category (41.6\%), compared to male (21.1\%). More than half of the married respondents were in moderate nomophobia level (55.8\%), and had a nomophobia in severe level (17.7\%).

35 of the D III or vocational respondents had moderate nomophobia (30.9\%). Similar condition can also be found in respondents with S1 + Profesi or professional (27.4\%) had moderate nomophobia. Respondents with more than 15 years of employment period had the most moderate level nomophobia (22.8\%). 
TABLE 4: Relationship between Demographic Data with Level of Nomophobia of Nurses in X Hospital Bandung ( $n=113)$

\begin{tabular}{llll} 
Variable & \multicolumn{2}{c}{ Level of Nomophobia } \\
\hline Age & p & r \\
Sex & 0.282 & -0.102 \\
\hline Marital Status & 0.425 & \\
\hline Educational Level & 0.580 & \\
\hline Employment Period & 0.891 & 0.021 \\
\hline Usage Period & 0.266 & -0.106 \\
\hline Usage Frequency & 0.691 & 0.038 \\
\hline Smartphone owned & 0.454 & 0.071 \\
Cost & 0.408 & 0.079 \\
\hline Self-efficacy & $0.012^{*}$ & $0.236^{*}$ \\
(* means on $\alpha$ 0.05; Cl 95\%) & $0.033^{*}$ & \\
\hline
\end{tabular}

All the respondents have nomophobia but in different levels. More than half of the respondents have moderate nomophobia (63.7\%), and 21 of the respondents have mild nomophobia (18.6\%).

\subsection{Relationship between Characteristics and Self-efficacy with Level of Nomophobia}

Table 4 showed that the cost expenses in a month had significant correlation with the level of nomophobia, with $p$ value $0.012(p<0.05)$ with coefficient of correlation 0.236 . Results of test between self-efficacy with level of nomophobia using Chi-Square test was found a significant correlation with $p=0.033(\alpha=0.05 ; \mathrm{Cl} 95 \%)$.

\section{Discussion}

\subsection{Relationship between Demographics and Nomophobia}

The results of testing the age with the level of nomophobia found no significant relationship. The results of this study are in line with study [6] which found that age did not affect the level of nomophobia of respondents. Different results are shown that younger ages are more likely to develop addiction to social networking or social media via smartphones [10]. Bartwal \& Nath also revealed statistically significant differences between different age groups with level of nomophobia [11]. The difference from the 
results of this study is possibly because of nomophobia can be found at all age levels and is not limited to one age group.

The results of gender testing and the level of nomophobia obtained an insignificant relationship. However, the mean value in female respondents (mean=82.17; SD=21.378) was a little higher than the male respondents' mean value (mean=76.61; SD=21.998). The results of this study are in accordance with [11] which states that there is no significant difference between sex and the level of nomophobia. The results of this study contradict with study that find significant relationship between gender and the level of nomophobia [12].

The difference in the results of this study was possibly because both men and women in the sample of this study chose to use smartphones as a method of reducing stress levels at work. This is in accordance with the statement that the increase in smartphone usage is caused by nurses experiencing emotional stress due to high workloads, changing shifts, high demands from patients, and low quality of sleep [6].

The results of testing marital status and the level of nomophobia showed that there was no significant relationship. Other research states that married individuals tend to reduce smartphone usage while working [13]. The difference in the results of the study may be due to family factors, this can be observed from the response of the respondent's item who worried that the family cannot contact them if they do not bring a smartphone (46\%).

The results of testing the variable level of education and level of nomophobia showed a meaningless relationship. It is different with study which stated that the higher the education level the higher the level of nomophobia is [13]. The differences between both results may be caused the education level of the respondents does not really influence the choice of information media sources. This is reinforced by the hospital's policy of implementing an Android-based information system that can be easily accessed via a personal smartphone.

The results of employment period testing and the level of nomophobia obtained a meaningless relationship. This study is in line with [14] which obtained a meaningless difference between smartphone usage and individual employment period. Factors that may affect the results of this study are the need of information sources and telecommunications which are not much different between new nurses and nurses who have worked for a long time. Besides, communication and information have become quite important priorities during this pandemic.

The testing result of the smartphone usage duration and the level of nomophobia showed no significant relationship. The results of this study were contradicted to 
Aguilera-Manrique that found a relationship between the smartphone usage duration and the level of nomophobia [6]. This is possible due to the feeling of security that is obtained by individuals when carrying a smartphone even though its use is relatively shorter. The same thing was expressed by Bülbüloğlu, et al. which explains that smartphones can contribute to users' sense of security [13].

The test results between the smartphone usage's frequency and the level of nomophobia were not significant. The results of this study are different from Mayasari which stated that the higher the usage frequency, the higher the level of individual nomophobia [2]. Study found that smartphone usage patterns contributed to the incidence of nomophobia [6]. The difference in results in this study requires further research. because the psychological condition of nurses may affect the frequency of using smartphones while working [6]. In addition, pandemic conditions create an increasing need for upto-date and reliable information.

The test results between the number of smartphones owned by the respondent and the level of nomophobia showed a less significant relationship. Possible factor that may influence the results is that more smartphones feature dual sim card slots, making it easier for individuals to choose to carry just one smartphone instead of carrying more than one smartphone.

The results of testing the costs incurred of smartphone usage with the level of nomophobia obtained a significant relationship. The results of this study are in line with the statements of Pradana, Muqtadiroh, \& Nisafani that individuals with nomophobia tend to pay large fees for their smartphones [2]. The sizeable monthly expenses may be caused by purchasing data packages with large capacities, and this is reinforced by the statement which states that individuals with nomophobia tend to panic when their internet quota runs out [15]. The need for a large internet quota may due to changes in learning methods or changes in working patterns at home due to the Covid-19 pandemic.

\subsection{Relationship of Self-Efficacy and the Level of Nomophobia}

The results of the bivariate analysis showed a relationship between self-efficacy and the level of nomophobia. The findings of this study are consistent with [8] and [9] stated that self-efficacy is one of the psychosocial protectors in overcoming anxiety. Individuals with nomophobia tend to show symptoms of anxiety [16, 7, 17].

Research stated that nomophobia can cause emotional exhaustion among workers. Individuals with nomophobia should have good level of self-efficacy so this will not have 
an impact on their performance $[18,19]$. This also confirmed by research that self-efficacy can build resilience toward anxiety [20].

Decrease in the performance of nurses will affect the quality of nursing care provided. Poor nursing care will have an impact on decreasing patient satisfaction and safety. Research stated that patient satisfaction is very important, because patient satisfaction is a linking factor between perceptions of service quality and patient intentions regarding service selection in the future [21].

The decline in nurses' performance can be prevented. One of the efforts that can be done to improve nurses' performance is through nursing practice education and training [22]. Gilissen, et al. argued that nursing education and practice will shape the self-efficacy of nurses, and improving the quality of nurses' self-efficacy is believed as very important in increasing the ability of nurses to provide care [23]. Self-efficacy is extremely important for nurses at work even though they experience symptoms of nomophobia.

\section{Conclusion}

This study found that nurses with low levels of self-efficacy showed higher levels of nomophobia. The results of this study can be used by hospitals as a consideration in drafting clear regulations regarding restrictions and prohibitions on the use of smartphones when nurses are working, as well as a consideration in determining the right program to increase and maintain the level of self-efficacy of nurses as an effort to improve service quality, satisfaction, and patient safety.

\section{Limitation}

This study was conducted in one hospital only, the study results could not be used as a reference to describe the characteristics of Indonesian nurse in general. This research may have bias data due to responses that are not fully in accordance with the actual situation. Polit and Beck states that respondents can hide their true responses and only provide answers that reflect social values or professional expectations [7]. In addition, the limited research related to similar topics makes it difficult to elaborate the results of the study. 


\section{Funding}

\section{Acknowledgement}

The authors would like to thank their colleague for their contribution and support to the research. They are also thankful to all the reviewers who gave their valuable inputs to the manuscript and helped in completing the paper.

\section{Conflict of Interest}

The authors have no conflict of interest to declare.

\section{References}

[1] Gökçearslan S, Mumcu FK, Haslaman T, Çevik YD. Modelling smartphone addiction: The role of smartphone usage, self-regulation, general self-efficacy and cyberloafing in university students. Computers in Human Behavior. 2016;63:639649. doi:https://doi.org/10.1016/j.chb.2016.05.091

[2] Sudarji S. Hubungan nomophobia dengan kepercayaan diri. Jurnal Psikologi Psibernetika. 2017;10:51-61.

[3] Walsh SP, White KM, Young RM. Young and connected: Psychological influences of mobile phone use amongst Australian youth. In Proceedings: International conference on social and cultural aspects of mobile phones, convergent media and wireless technologies (pp. 125-134) 2007.

[4] Montgomery S. Nurses using smartphones and tablets at work. 2019. Available from: https://www.workingnurse.com/articles/Nurses-Using-Smartphones-andTablets-at-Work

[5] Mobile device internet and social media use and habits survey report. Wolters Kluwer Health; 2014. Available from: http://www.lippincottsolutions.com/sites/default/files/wolters_kluwer_mobile_internet_and

[6] Aguilera-Manrique G, Márquez-Hernández VV, Tania A-C, Granados-Gámez G, Gutiérrez-Puertas V, Gutiérrez-Puertas L. The relationship between nomophobia and the distraction associated with smartphone use among nursing students in their clinical practicum. PLoS One. 2018;13(8). http://dx.doi.org/10.1371/journal.pone.0202953 
[7] Gutiérrez-Puertas L, Márquez-Hernández VV, São-Romão-Preto L, Granados-Gámez G, Gutiérrez-Puertas V, Aguilera-Manrique G. Comparative study of nomophobia among Spanish and Portuguese nursing students. Nurse Education in Practice. 2019;34:79-84. http://dx.doi.org/10.1016/j.nepr.2018.11.010

[8] Bandura A. On the functional properties of perceived self-efficacy revisited. Journal of Management. 2012;38(1):9-44. doi:10.1177/0149206311410606

[9] Stuart GW. Principles and practice of psychiatric nursing. 10 $0^{\text {th }}$ ed. Saint Louis: Elsevier; 2013.

[10] Kuss DJ, Griffiths MD. Social networking sites and addiction: Ten lessons learned. International Journal of Environmental Research and Public Health. 2017;14(3):311.

[11] Bartwal J, Nath B. Evaluation of nomophobia among medical students using smartphone in north India. Medical Journal Armed Forces India. 2019. https://doi.org/10.1016/j.mjafi.2019.03.001

[12] Daei A, Ashrafi-rizi H, Soleymani M. Nomophobia and health hazards: Smartphone use and addiction among university students. International Journal of Preventive Medicine. 2019;10(1):202. http://dx.doi.org/10.4103/ijpvm.IJPVM_184_19

[13] Bülbüloglu S, Özdemir A, Kapıkıran G, Sarıtas S. The effect of nomophobic behavior of nurses working at surgical clinics on time management and psychological wellbeing. Journal of Substance Use. 2019:1-6. doi:10.1080/14659891.2019.1692926

[14] Abolfotouh MA, Bani Mustafa A, Salam M, Al-Assiri M, Aldebasi B, Bushnak I. Use of smartphone and perception towards the usefulness and practicality of its medical applications among healthcare workers in Saudi Arabia. BMC Health Services Research. 2019;19(1):826. doi:10.1186/s12913-019-4523-1

[15] Askari S, Delavar A, Farhangi AA. The relationship between mobile consumption pattern and "no mobile phobia" among mobile users in Tehran. Scientific Journal Management System. 2017;6(4):197-224.

[16] Dixit S, Shukla H, Bhagwat A, et al. A study to evaluate mobile phone dependence among students of a medical college and associated hospital of central India. Indian Journal of Community Medicine: Official Publication of Indian Association of Preventive \& Social Medicine. 2010;35(2):339-341. doi:10.4103/0970-0218.66878

[17] Yildirim C, Correia A-P. Exploring the dimensions of nomophobia: Development and validation of a self-reported questionnaire. Computers in Human Behavior. 2015;49:130-137. doi:10.1016/j.chb.2015.02.059

[18] Arora A, Chakraborty P. Diagnosis, prevalence and effects of nomophobia - A review. Psychiatry Research. 2020;288:112975. https://doi.org/10.1016/j.psychres.2020.112975 
[19] Chakraborty N. The COVID-19 pandemic and its impact on mental health. Progress in Neurology and Psychiatry. 2020;24(2):21-24. doi:10.1002/pnp.666

[20] St. Hilaire C, Clarence SH. The social dimensions of the preventive efficient stress situation model (PRESS) questionnaire in light of the general self-efficacy, health belief model, the theory of care-seeking behavior, and symbolic interactionism in healthcare. Cogent Social Sciences. 2016;2(1). doi:10.1080/23311886.2016.1234669

[21] Gishu T, Weldetsadik AY, Tekleab AM. Patients' perception of quality of nursing care; A tertiary center experience from Ethiopia. BMC Nursing. 2019;18(1):37-36. doi:10.1186/s12912-019-0361-z

[22] Pirani S. Implementation of a wound care education project to improve the wound care competency among psychiatric nurses: A quality improvement project and feasibility study. Journal of Psychiatric and Mental Health Nursing. 2020. doi:10.1111/jpm.12629

[23] Gilissen J, Pivodic L, Wendrich-van Dael A, et al. Nurses' self-efficacy, rather than their knowledge, is associated with their engagement in advance care planning in nursing homes: A survey study. Palliative Medicine. 2020;34(7):615-924. doi:10.1177/0269216320916158 